\title{
Analysis on Financing Strategy of Small and Micro Enterprises in Qingdao
}

\author{
Sun Jingjing \\ Qingdao University of Technology 266300
}

Keywords: Qingdao; Small and micro enterprises; Financing; Strategy

\begin{abstract}
In recent years, China facing the impact of the global financial crisis, the economic situation is grim, small and micro enterprises, as important parts of the national economy, are the key points for social stability and economic healthy development. In order to cope with the complex economic situation at home and abroad, the government of Qingdao issued related policies to increase employment, and promote enterprise innovation, which make the rapid development of small and micro enterprises. At present, the loan rate of small and micro enterprises in Qingdao has been improved, that shows a good development sign. However, most of small and micro enterprises are still in the growth period, and they are always troubled with the difficulties of financing. Based on the root reasons why it's so difficult for small and micro enterprises to finance, this paper will analyze the current financing status of Qingdao small and micro enterprises, and put forward suggestions for their financing strategies by focusing on the enterprises themselves, the government, and the exploration of financing channels.
\end{abstract}

\section{Preface}

In the modern industrial structure, small micro enterprises can be seen as the main pillar of the national economy and also a special group full of vibrant and technological innovation. Cultivating suited growth soil for small and micro enterprises, not only benefits the progress of national creative ability, but also promotes China's economic strength and scientific research ability. The way to solve the financing problem of small and micro enterprises has been the focus of global concerns. Especially under the tightening environment of the world economy, because of the effect of their own growing shortcomings, small micro enterprises mainly rely on traditional bank financing channels, that causes the unavoidable issues of limited financing channels and high financing cost which result in the difficulties of expanding enterprise scale, thereby restrict the national economic stable and harmonious development ${ }^{[1-2]}$.

There are many factors that can lead to small micro enterprises' financing predicament. For instance, enterprises cannot obtain loans from formal financial institutions due to poor credit or lack of collateral; private lending with low loan requirements is useless at risk control and has high financing cost which is extremely easy to meet the dead; government departments do not issue relevant encourage and preferential policies, as well as the supervision and management mechanism does not make a guarantee to the growth and development of small and micro enterprises. At present, small and micro enterprises have played an important role for the economic development in Qingdao, middle and small of individual private economy has been accounted for half of the city's total economy ${ }^{[3]}$. The achievements on broadening the small micro enterprises' financing channels in Qingdao go well ahead of other areas in Shandong. Currently, small financial service coverage is steadily expanding, and the number of small micro enterprises' loan continues to grow, leading the whole market environment active, and strengthening supports of all parties ${ }^{[4]}$. Qingdao makes supportive and incentive policies for small and micro enterprises in terms of tax and employment etc. Through dredging vascular necrosis in the financing link by multi channels, it is the critical factor to provide nutrition and blood for the successful growth of small and micro enterprise. Based on the influence factors of small micro enterprises' financing difficulties and the current financing situation of small micro enterprises in Qingdao, this paper discusses relevant financing strategies of small and micro enterprises, analyze how small and micro enterprises can take measures to improve 
their own ability and get rid of financing problems. Meanwhile, it gives some inspirations and references to those who face with the same financing difficulties in other regions of Shandong Province, as well as enhance their confidence to solve the financing problems.

\section{The root causes of small and micro enterprises financing difficulties}

\subsection{Self disadvantages of small and micro enterprises}

Since the advocate and encourage entrepreneurship, the emerging private small and micro enterprises have sprung up. Now the speed of social information is accelerated, epochal industries of technology and electronic commerce have increased in addition to the majority of the traditional industries.

These small and micro enterprises have the biggest characteristic is "young", this characteristic is their own pain points and deficiencies. Firstly, because of "young", so the operation is small, there is not enough capital, there is no certain reputation, there is no perfect management and service system, and there are no more wide financing channels. If due to the preferential policies or their own capital through the early venture stage, then can they develop continuously? And how can they achieve sustainable development? Funds became a most important problem, and capital operation of the main channel is bank loans, but due to a number of small and micro enterprises management is not standardized, low level of credit, increase the cost of the risk management of financial institutions. Secondly, small and micro enterprises with their own narrow profit margins, unable to obtain adequate collateral loans, especially some traditional industries, only through weaken the product profits to obtain the value of the business, small scale and collateral less ${ }^{[5]}$. At the same time, the interest rate of private lending is generally higher. Although it can alleviate the small and micro enterprises' temporary working capital demand in a certain extent, the increased cost and risk of financing is not conducive to the rapid and healthy development of the small and micro enterprises with deficiencies. Therefore, small and micro enterprises often due to their own lack of "too young", leading to difficulties in financing.

\subsection{The influence of government policy}

In recent years, the government is also promoting the birth and growth of small and micro enterprises by introducing relevant support and incentive policies. But most governments are not doing their best to support the growth of small and micro enterprises. Just give some preferential policies in the early stage of entrepreneurship, such as reducing the registered capital of small and micro enterprises, tax relief for one year or six months, but the follow-up service is not in place. For example, nobody will take care of the matter after financing supports which results in the situation like "the master get started, practice by individuals". Most of the small and micro enterprises in the region are increasing year by year, but in addition to the basic support policies, other relevant legal system has not kept up, resulting in some of the weak competitiveness of small and micro enterprises operating difficult. The lack of relevant policies and legal guarantees of the actual business subsidies, vocational skills subsidies, and small-sum guaranteed loans. The financing system is not perfect, not conducive to the establishment of small and micro enterprises credit system platform. The financing channels are still not broadened, the cost of borrowing does not decrease, capital operation is not smooth, and financing problem is still outstanding.

\subsection{Impact of financial institutions}

Strengthening the financial services of small and micro enterprises is an important measure for the banking industry to support the development of the real economy; it is also an urgent need for banking industry to achieve sustained and healthy development. However, due to the small and micro enterprises restricted by capital and operating scale, and competitiveness is not strong, anti-risk ability is poor, banks and other financial institutions to small and micro enterprises loans act very cautiously, which leads to credit crunch phenomenon ${ }^{[6]}$. For the sake of the interests of commercial banks themselves, some small and micro enterprises with bad credit increasingly unable to get financial support, some development prospects are not promising industry, financing difficulties and high cost of financing problem become more prominent. 


\section{Financing status of small and micro enterprises in Qingdao City}

\subsection{The current situation of small and micro enterprises}

At present, Qingdao City has a large number of active small and micro enterprises. In 2015, the city's total market players rose $27.51 \%$, new market players registered capital increased by $46.71 \%$, new market players to absorb employment compared to the number of growth $294.02 \%$, it played an important role in promoting Qingdao stable economic development. Thus small micro enterprises' contribution to society and the economic construction have become increasingly prominent, absorb employment and stable social contribution role continuously rising, the ability of technological innovation continue to enhance, $\mathrm{R} \& \mathrm{D}$ investment and proportion are greatly increased. The model of small and micro enterprises with low cost, low value-added products to occupy the competitive advantage has been effectively improved. With continuous optimization of the industrial structure, the traditional industries accelerate the development of high-tech industries, emerging industries and modern services and other fields. Enterprise management capabilities continue to rise steadily. Due to government organized the implementation of small micro enterprise business incubation programmed, and cooperated with universities for entrepreneurs and senior management personnel training. Strategic vision for entrepreneurs and business philosophy are increased significantly, the management level is enhanced, and an enterprises' group of operating norms, managing scientifically, and growing well is formed ${ }^{[3-5,7]}$

\subsection{The government wholeheartedly supports the growth of small and micro enterprises.}

Recently, the Qingdao municipal government office issued "a notice on further clarify the issue of urban and rural employment and entrepreneurship policy"(Green Office No. [2014]19), introduced 20 measures, in the first implementation of the integration of urban and rural policy to support and encourage entrepreneurship and employment. Integration of urban and rural policy innovation and entrepreneurship subsidies can receive up to 15,000 Yuan, the maximum loan amount of small-sum guaranteed loan is 3 million Yuan. After policy implementation, further reduce the threshold, optimize the administrative examination and approval service, all conform to the conditions of urban and rural workers in the city can enjoy preferential policies.

Qingdao municipal government set innovation as the important part of all-round development, pay special attention to communication and docking, reform decree platform, as well as the construction of Qingdao becomes "the city of innovation, the metropolis of entrepreneurship, and the island of business men". In order to support the growth of small and micro enterprises, the government continued to improve the financing structure, expand the financing channels. Support the establishment of credit system platform, increase the financing channels for the network, the establishment of small and micro enterprise network revolving loan, to meet the small and micro enterprises with financing characteristics with borrowed, greatly improve the efficiency of the use of funds at the same time, and reduce the small and micro enterprises borrowing costs ${ }^{[5]}$.

\subsection{Financial environment}

In recent years, under the jurisdiction of the banking industry and other financial institutions to work together, Qingdao small and micro enterprises loans gradually increased, highlighting the good trend of development. Large banking institutions, local legal institutions are the main institutions lending to Qingdao small and micro enterprises. In local legal institutions and the new rural financial institutions, small and micro enterprises loans accounted for the highest proportion of all corporate loans, the characteristic for small and micro enterprises is significant.

Bank loan is still an important financing channel for small and micro enterprises in Qingdao, to support the development of small and micro enterprises is also an important part of the bank's business. In Qingdao, "Baotuan trust” credit platform takes small and micro enterprise development service center as a borrower, with assurance company together to form a common platform, provide financing guarantees for small and micro enterprises. This kind of financing method breaks through the bottleneck of the traditional single small and micro enterprise guarantee limit, which is the initial remission for the financing difficulty of small and micro enterprises in Qingdao city. Under the impact of the financial crisis, although bank financing products launched more frequently, some of the big banks still treat their own interests as the basic starting point, risk control always to be 
very tight, so that the small and micro enterprises to obtain bank loans support difficulty is still large, financing is still difficult ${ }^{[5,7-8]}$.

\section{Analysis of the financing means of small and micro enterprises in Qingdao City}

\subsection{Self-improvement of small and micro enterprises by holding financing opportunities.}

In government efforts to support small and micro enterprises, under the favorable environment for small and micro enterprises escort, small and micro enterprises should seize the opportunities for development, according to the problems faced by their own to make relevant countermeasures. For example, in the face of their own shortcomings, they should strive to improve and practice. Positive attention and flexible use of government issued preferential policies, to ease the financing difficulties in the early stage. Organizing the staff to participate in employment skills training, senior personnel manager in training, training strategic vision, enhance the management capacity, change the weak enterprise culture, strengthen the brand and technology innovation, to enable enterprises to enter the benign development, high credibility, the overall good, sufficient internal resources, then, the financing channels will expand naturally ${ }^{[9]}$.

This made a very good example to other parts of the government, since small and micro enterprise is active and with special value of the new force in the period of social transformation, we should respond to the national policy, complied with the time development, do a good job to support small and micro enterprises, promote the development of regional economic and our society.

\subsection{Improve the government regulation and control system.}

Financial market is not mature, small and micro enterprises are facing an imperfect credit system, weak legal awareness of the financing environment. This is very detrimental to those enterprises that already have financing difficulties. In this case, the government should improve the mechanism to play the government's regulatory constraints, so that small and micro enterprises to reduce the risk of loans, at the same time, support and encourage local financial institutions to issue small and micro enterprises special financial bonds in order to spread the risk.

The government should improve the small and micro enterprise credit system, take social credit system construction as the focus of improving the financial credit environment, and create a good environment for small and micro enterprises credit rating and credit applications. In addition, the government should improve the relevant legal provisions and industry guidance documents, better the legal environment. With legal protection measures, commercial banks are likely to reduce the credit risk prevention, and eliminate the worries of small and micro enterprise loans. Therefore, relevant industry guidance documents and legal provisions can not only reduce the risk of loans, but also to form a stable credit mechanism to protect the bank ${ }^{[10]}$.

\subsection{Framework of a reasonable financing market, enhance the level of commercial banks lending to small and micro enterprises.}

Under the background of the current financing difficulties and financing expensive of small and micro enterprises, the policy banks should be established as an effective complement to the current financial market structure. When the small micro enterprise financing market failure, policy banks can play a policy role, combined with national policy to determine a more reasonable pricing model and credit model, ease the financing difficulties of small and micro enterprises to a certain extent.

Commercial banks adhere to the principles of market and business sustainability, in the context of the optimization of the structure of economic restructuring, commercial banks need for innovative loans and products in order to support the development of small and micro enterprises in Qingdao. Commercial banks should be based on the risk level of small and micro enterprises, different types of enterprises, different stages of development and other objective status quo, targeted launch of loan products ${ }^{[11]}$. At the same time, commercial banks should pay attention to the improvement of capital use efficiency, optimize the allocation of all kinds of resources; improve the professional service system of Qingdao city commercial bank. Commercial banks need to consider whether the loan of small and micro enterprises can bring social or economic value, and make their financing needs to be met as much as possible. 


\section{Conclusion}

The lifeblood of Chinese economy lies in the steady development of small and micro enterprises. Qingdao city has done better in promoting small and micro enterprises to self growth, improving preferential tax policies and broadening the financing channels for enterprises. From encouraging and supporting the development of small and micro enterprises, to the introduction of specific policies and related service system, Qingdao city make a lot of efforts and methods of innovation in order to promote the development of the new force of small and micro enterprises. In the future, other regions should also take the opportunity to build a service oriented government, add specifically for small and micro enterprise services departments, or establish independent policy banks, maintain fair competition, and create a favorable environment for the healthy development of small and micro enterprises.

\section{Fund Project}

The humanities and social sciences research project of Shandong Province, the financing strategy analysis of small and micro enterprises in Qingdao. (J13WF80)

\section{Reference}

[1]Wang Yanan. Research on Legal Issues of Credit Guarantee System for Small and Micro Enterprises in China [D]. Guangxi University, 2014.

[2] Sha Yong. Financing Difficulties and Countermeasures of Small and Micro Enterprises in China [J]. Jianghai Academic Journal, 2013, (03): 99-104.

[3] Zhao Xuexia. Research on Financing Problems of Small and Medium Sized Enterprises in Qingdao [D]. Southwestern University of Finance and Economics, 2012.

[4] Niu Jianxiang. Research on Financing Problems of Small and Micro Enterprises in Qingdao [D]. Anhui University, 2014.

[5] Han Guangqiang, Xia Qing, Wang Hongjun. A Study on the Financing Strategy of Small and Micro Enterprises in the Coastal Economic Belt of Liaoning Province Based on Growing Period [J]. Economic Research Reference, 2014, (28):68-74.

[6] Wang Xiaoyan, Hou Lei. Research on Financing Strategy of Small and Micro Enterprises Taking Tianjin City as an Example [J]. Finance and Accounting Communication, 2015, (2):29-32.

[7] Liu Zhiting. Research on Problems and Countermeasures of Small and Medium Sized Enterprises in Qingdao City [J]. Journal of Qingdao Technical College, 2010, (3):16-18,27.

[8] Yu Yang. Research on Financing Problems of Small and Micro Enterprises in China [D]. Jilin University, 2013.

[9] Jiang Yujuan. Study on Financing Problems of Small and Micro Enterprises in China [D]. Sichuan Normal University, 2014.

[10] Cui Jianwei. Research on Financing Problems of Small and Micro Enterprises [D]. Southwestern University of Finance and Economics, 2013.

[11] Mo Xiao Feng. Study of the Financing Strategy of Guangxi Small and Micro Enterprises [D]. Guangxi University, 2012. 